\title{
THE EFFECT OF MULTIWALLED CARBON NANO TUBES ON CURE KINETICS OF EPOXY RESIN
}

\section{BHUKYA RAJAM}

Research Scholar, University College of Technology, Osmania University Hyderabad, India

The effects of incorporation of multiwall carbon nano tubes (MWNTs) on the cure reaction of a diglycidyl ether of bisphenol-A (DGEBA) and triethylene tetramine (TETA) as a curing agent have been studied with an isothermal differential scanning calorimetry (DSC) technique.

Kinetic analysis was performed with the phenomenological model of Kamal and Sourour. Isothermal kinetic parameters were determined and the results show that the kinetically controlled parts of reaction could be expressed well with Kamal and Sourour model while end of curing reaction is diffusionally controlled.

Activation energies and kinetic parameters are determined by fitting experimental data for MWNTs/epoxy Nano composites, the initial reaction rate increases and the time required for the maximum rate decreases with increase in MWNTs contents, because of the acceleration effect of MWNTs.

The initial rates of MWNTS/Epoxy Nano composites were found to be comparatively higher than that of neat Epoxy at all curing temperatures, whereas the time required to the maximum reaction rate of the Nano composites decreased with increasing MWNTs content, suggesting that MWNTs have an acceleration effect on the Epoxy cure reaction.

Compared with the neat DGEBA/TETA Epoxy, the MWNTs/Epoxy Nano composites exhibited lower activation energies for $k 1$, and $E 1$ and decreased with increasing MWNTs. E2 for The MWNTs/Epoxy Nano composites remained the same as that of the neat Epoxy.

The further reaction kinetic analysis indicates that the Kamal model can well fit the reaction rate at the kinetic controlled stage which is about $60 \%$ conversion and rest of the reaction is diffusion ally controlled.

KEYWORDS: MWNT, DGEBA, TETA, DSC, CNT, SWNT
\end{abstract}

Received: May 19, 2020; Accepted: Jun 09, 2020; Published: Jul 25, 2020; Paper Id.: IJMPERDJUN2020454

\section{INTRODUCTION}

Figure 1 shows Carbon nano tube (CNT) is a fullerene related structure which consist of graphene cylinders closed at either end with caps containing pentagonal rings

Figure 2 shows CNTs have a unique atomic structure, very high aspect ratio, and extraordinary mechanical properties (strength and flexibility) makes them ideal reinforcing fibers in Nano composites.

Carbon nano tubes are of two types 1) Single walled carbon nano tube 2) Multi walled carbon nano tube 


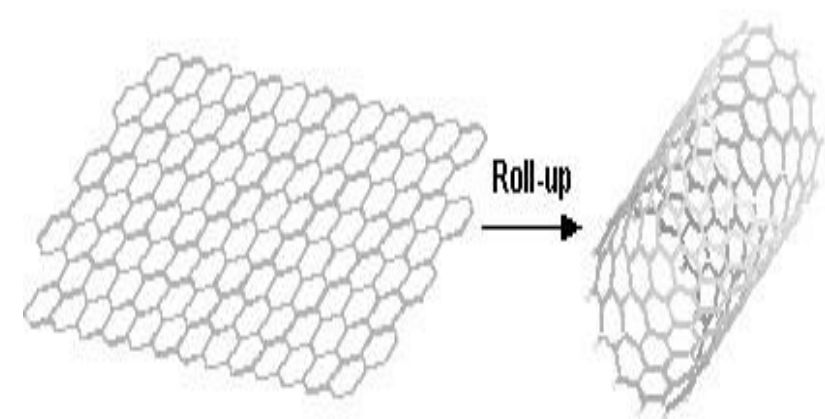

graphene sheet

SWNT

Figure 1: Rolled Graphene Sheet.

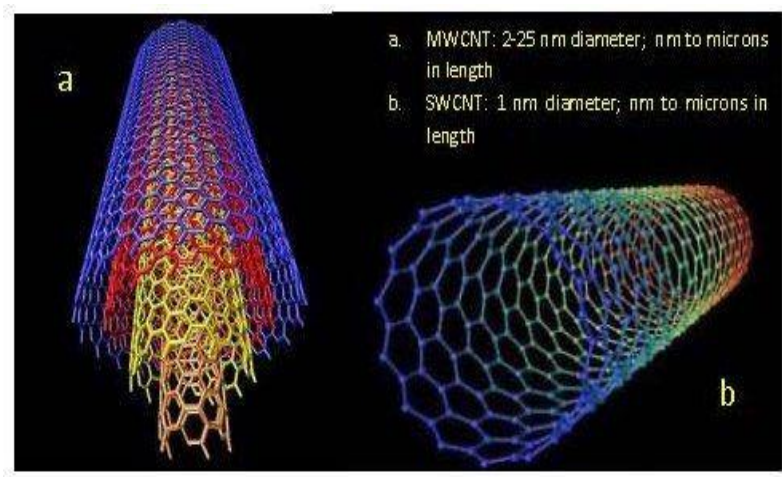

Figure 2: a) Multi Walled Carbon Nano Tube.

b) Single Walled Carbon Nano Tube.

\section{PROPERTIES OF CNT}

Elastic modulus: $\sim 1 \mathrm{Tpa}$; Tensile strength: $\sim 50 \mathrm{Gpa}$;

Thermal conductivity: > 1,500 W/m K, much higher than $\mathrm{Cu}-400 \mathrm{~W} / \mathrm{m} \mathrm{K}$; Electrical conductivity: Better than $\mathrm{Cu}$;

Elongation: > $30 \%$;

Density: $<1.2 \mathrm{~g} / \mathrm{cm} 3$ for single-wall CNTs, $2.0 \mathrm{~g} / \mathrm{cm} 3$ for multi-wall CNTs.

Epoxy is also known as poly epoxide, is a thermosetting polymer formed from a reaction of an epoxide resin with polyamine hardener. Epoxy resins are the most important thermo sets, widely used as adhesives, coatings, and composite materials. To enhance or provide physical properties, such as modulus, thermal expansion, thermal and electrical conductivity, and magnetic recording properties, reinforced fillers, such as carbon black, carbon fibers and glass fibers are incorporated in the resins. In recent years, the use of carbon nano tubes (CNTs) in epoxy resin /carbon nano tube composites has attracted a great deal of attention. CNTs

Have a unique atomic structure, very high aspect ratio, and extraordinary mechanical properties (strength and flexibility) making them ideal reinforcing fibers in Nano composites.

\section{EXPERIMENTAL}

\subsection{Aim of the Present Work}

The aim of the present work is to study the cure kinetics of Epoxy resin (diglycidyl ether of bisphenol A-based-DGEBA) polymerized with an amine (triethylene tetramine-TETA) and DGEBA/TETA-MWNTS. Determination of experimental data 
for both the neat DGEBA/TETA system and for epoxy/MWNTs Nano composites Kinetic analysis will be performed with the phenomenological model of Kamal and Sourour. Determination of activation energies and kinetic parameters by fitting experimental data.

\section{MATERIALS}

- Resin: Diglycidyl ether of bisphenol-A (DGEBA)

- Hardener: Tri ethylene tetramine (TETA)

- MWNTs (Master batch): EPOCYL

\subsection{Specimen Preparation}

A 2 wt $\%$ of master batch was added to $88 \%$ of Epoxy resin (DGEBA) and 10\% of TETA was slowly added with continuous hand mixing until a homogeneous mixture was observed, which took about $10 \mathrm{~min}$. Several DSC aluminum pans were filled with the reaction mixture. The samples $(20 \mathrm{mg})$ were then cooled and stored in a freezer until required.

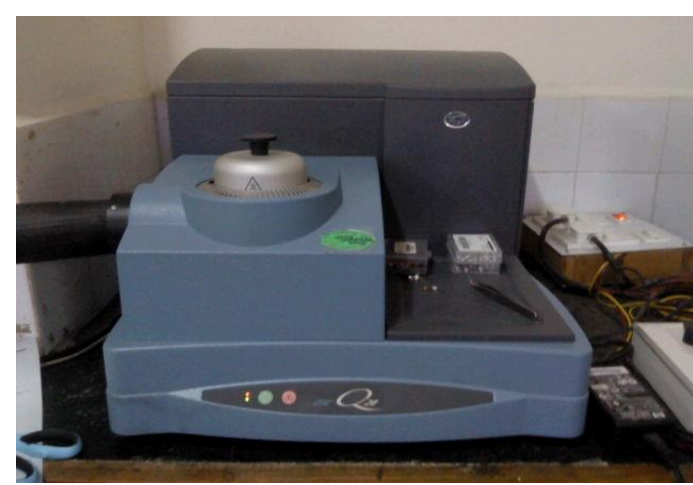

Figure 3: Differential Scanning Calorimeter.

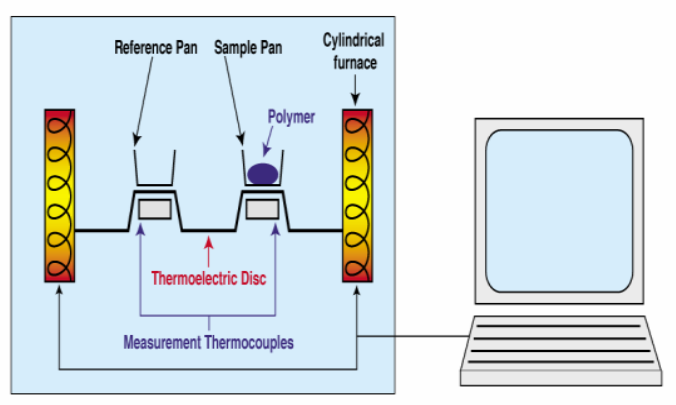

Figure 4: DSC System for a Polymer Sample.

\section{EXPERIMENTAL PROCEDURE}

A differential scanning calorimeter (DSC Q20 TA instruments) was used for the dynamic and isothermal cure experiments and for data analysis under a nitrogen flow of $50 \mathrm{ml} / \mathrm{min}$. In dynamic scan $20 \mathrm{mg}$ of samples were heated from room temperature to $300^{0} \mathrm{c}$ at a heating rate of

$10^{0} \mathrm{c} / \mathrm{min}$. In an isothermal scan each sample was ramped from room temperature to the desired isothermal temperature and then held isothermally. The isothermal experiments were conducted at three temperatures $\left(80,85\right.$ and $\left.90^{0} \mathrm{c}\right)$. 
The reaction was considered complete when the signal leveled off to baseline. The total area under the exotherm curve, based on extra polated base line at the end of the reaction was used to calculate the isothermal heat of reaction $\mathrm{Ht}(\mathrm{J} / \mathrm{g})$, at a given temperature.

\section{RESULTS AND DISCUSSIONS}

The reaction rate, $\mathrm{d} \alpha / \mathrm{dt}$ as a function of time, $\mathrm{t}$, was calculated from the measured heat flow $\mathrm{dH} / \mathrm{dt}$ in isothermal DSC experiments by:

$=$

Where $\alpha$ is the extent of reaction (conversion) and $\mathrm{Ht}$ is the total heat of reaction obtained from isothermal scan. Assuming proportionality between the extent of the reaction and the heat evolved up to a time $t$, a general expression for the extent of the reaction, $\alpha$, can be written as:

$\alpha=$

Where $\mathrm{H}_{\mathrm{p}}$ is the heat evolved up to a certain time in an isothermal experiment.

Epoxy resin curing can be divided into two general categories: $\mathrm{n}^{\text {th }}$ order and autocatalytic. The nature is typically autocatalytic in all cases, with the maximum reaction rate after the start of the cure reaction.

The phenomenological model developed by Sourour and Kamal was used. The reaction rate, $\mathrm{d} \alpha / \mathrm{dt}$, and the extent of the reaction, $\alpha$, are related to one another as follows:

Where $m$ and $n$ are the kinetic exponents of the cure reaction and $m+n$ represents the overall reaction order. The rate constants are $\mathrm{k} 1$ and $\mathrm{k} 2$ with two different activation energies and two pre- exponential factors.

The constant $\mathrm{k} 1$ in this equation can be calculated from the initial reaction rate at $\alpha=0$.The rate constants $\mathrm{k} 1$ and $\mathrm{k} 2$ are assumed to be constant at a given temperature and follow an Arrhenius temperature dependence:

$\mathrm{k}=\mathrm{A} \exp (-\mathrm{E} / \mathrm{RT})$

IWhere $\mathrm{A}$ is the pre-exponential factor, $\mathrm{E}$ is the activation energy, $\mathrm{R}$ is the gas constant, and $\mathrm{T}$ is the absolute temperature

Curve fit is conducted by the help of nonlinear least squares fitting (NLSF) method to compute the four parameters $\mathrm{k} 1, \mathrm{k} 2, \mathrm{~m}$ and $\mathrm{n}$ from the experimental data. The results are shown in the Table 1.

Table 2 shows a plot of the rate constants, $\mathrm{k} 1$ and $\mathrm{k} 2$ with corresponding temperature(1/RT) gave a straight line. From the slope of the straight line, the associated activation energies E1 and E2 were calculated. According to Arrhenius equation, $\mathrm{A}_{1}$ and $\mathrm{A} 2$ can be obtained.

Figure 8 shows that according to the Kamal model, the calculated data from the model are in good agreement with the experimental results at range of $060 \%$ conversions. At end of curing reaction $(\alpha>60 \%)$, Kamal model are not in proper agreement with experimental data which indicates that the curing mechanism started to change from chemical kinetics control to control by diffusion. This is because of the phenomena of gelification, vitrification, and high viscosity exist in the reaction medium at the end of curing process [43]. 


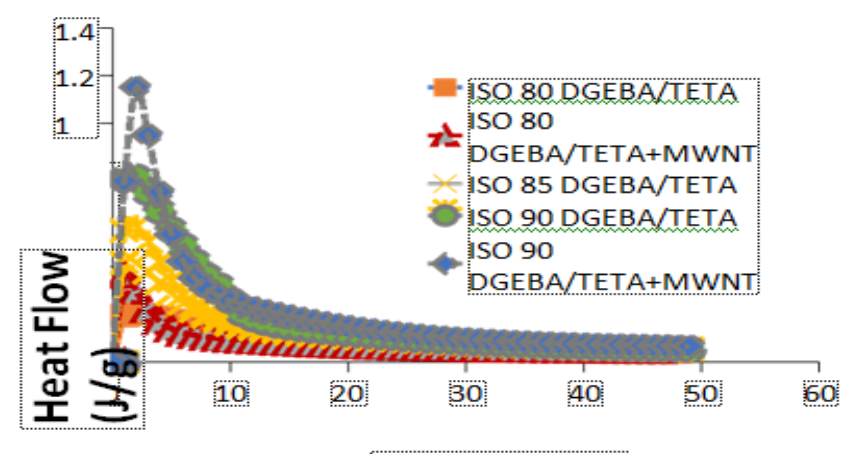

\section{Time (min)}

Figure 5: Heat Flow Versus Time for DGEBA / TETA Epoxy and Its Nano Composites.

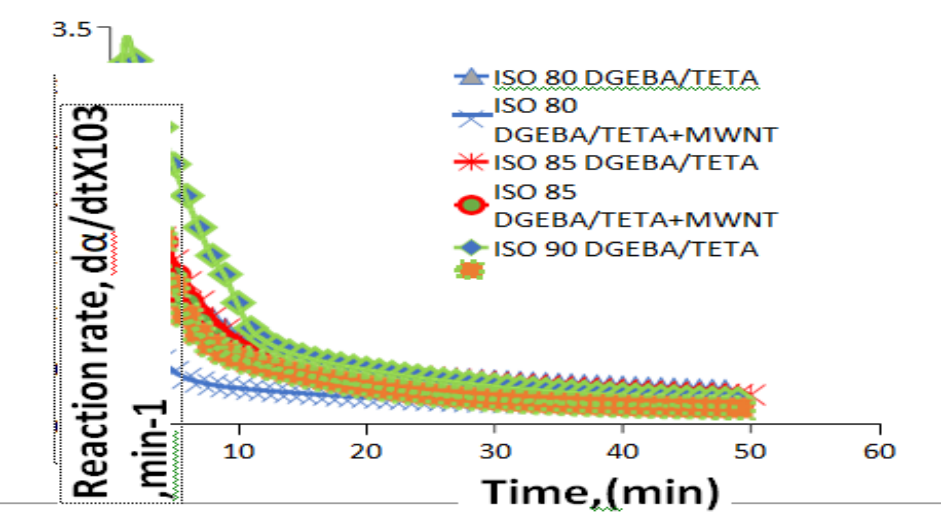

Figure 6: Reaction Rate Versus Time for DGEBA / TETA Epoxy and Its Nano Composites.

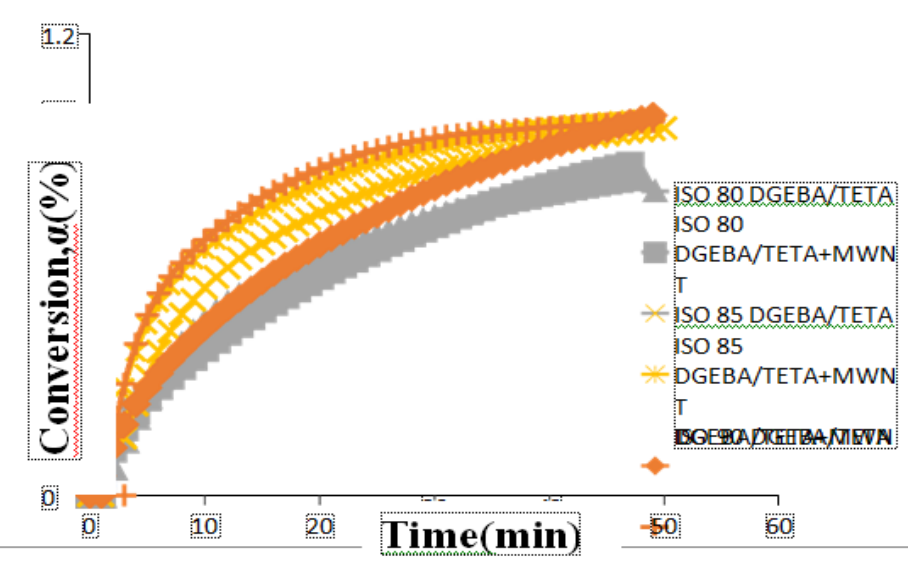

Figure 7: Conversion Versus Time of DGEBA / TETA Epoxy and its Nano Composites. 


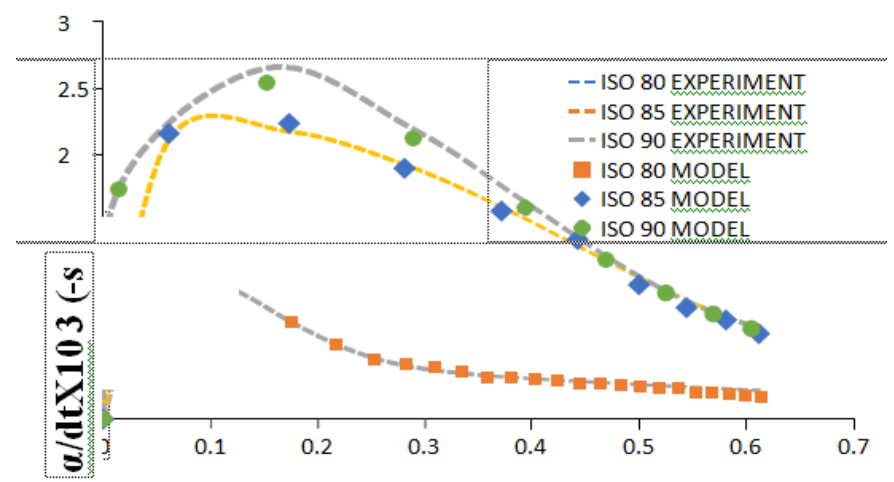

Figure 8: Comparison of Experimental Data with the Kamal Model in DGEBA / TETA + MWNTs.

Table 1: Kinetic Parameters K1, K2, M, N and M + N for Each MWNTs / Epoxy Nano Composite

\begin{tabular}{|c|c|c|c|c|c|c|}
\hline MWNTs & Temp & k1 X & $k 2 X 10^{4}$ & $\mathbf{m}$ & n & $\mathbf{m}+\mathbf{n}$ \\
\hline \multirow[t]{3}{*}{$(w t \%)$} & $\left(\mathbf{0}_{c}\right)$ & $10^{6}$ & $(\min -1)$ & & & \\
\hline & & (min- & & & & \\
\hline & & 1) & & & & \\
\hline \multirow[t]{5}{*}{0} & 80 & 4.552 & 22.44 & 0.086 & 1.679 & 1.765 \\
\hline & & 4 & & 2 & 4 & 6 \\
\hline & 85 & 1.518 & 36.246 & 0.204 & 1.851 & 2.055 \\
\hline & & 2 & & 1 & 5 & 6 \\
\hline & 90 & 0.6949 & 54.9118 & 0.2989 & 2.0495 & 2.3484 \\
\hline \multirow[t]{3}{*}{2} & 80 & 7.2832 & 23.642 & 0.0912 & 1.6245 & 1.7157 \\
\hline & 85 & 2.366 & 36.943 & 0.2132 & 1.7428 & 1.956 \\
\hline & 90 & 0.7814 & 56.432 & 0.3276 & 2.2468 & 2.5744 \\
\hline
\end{tabular}

$-1 / \mathrm{RT},(\mathrm{J} / \mathrm{mol})-1$

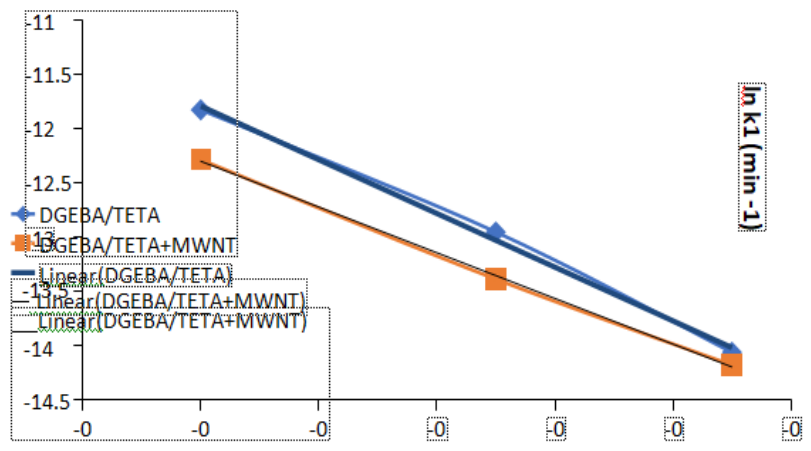

Figure 9: Curves of ln k1 Against 1/RT for Neat DGEBA /

TETA Epoxy and $2 \%$ MWNTs Nano Composites.

Table 2: Activation Energies and Pre-exponential Factors for Each MWNTs/Epoxy Nano Composite

\begin{tabular}{|c|l|l|l|l|}
\hline MWNTs $(w t \%)$ & $E_{I}(\mathrm{~kJ} / \mathrm{mol})$ & $E_{2}(\mathrm{~kJ} / \mathrm{mol})$ & $\ln \mathbf{A}_{1}$ & In $\mathbf{A}_{2}$ \\
\hline 0 & 247.062 & 96.363 & 95.797 & 26.705 \\
\hline 2 & 210.3 & 99.231 & 83.830 & 27.634 \\
\hline
\end{tabular}




\section{CONCLUSIONS}

The initial rates of MWNTS / Epoxy Nano composites were found to be comparatively higher than that of neat Epoxy at all curing temperatures, whereas the time required to the maximum reaction rate of the Nano composites decreased with increasing MWNTs content, suggesting that MWNTs have an acceleration effect on the Epoxy cure reaction.

Compared with the neat DGEBA/TETA Epoxy, the MWNTs/Epoxy Nano composites exhibited lower activation energies for k1, and E1 and decreased with increasing MWNTs. E2 for the MWNTs / Epoxy Nano composites remained the same as that of the neat Epoxy.

The further reaction kinetic analysis indicates that the Kamal model can well fit the reaction rate at the kinetic controlled stage which is about $60 \%$ conversion and rest of the reaction is diffusionally controlled.

\section{REFERENCES}

1. PA, Warrington, Microscopy and Hisology Catalog, polysciences, 19931994.

2. N.Itoh, in Functional Thin filems and Functional Materials : New Concepts and Technologies, ed. D.L. Shi, Tsinghua University Press and Springer-Verlag, P.Berlin, 1, 2003.

3. S. Iijima and T.Ichihashi, Nature 363, 603 (1993).

4. Golshahr, Alireza, et al. "Multiwall carbon nanotube reinforced silicone for aerospace applications." Int. J. M ech. Prod. Eng. Res. Dev 8.4 (2018): 743752.

5. P.M. Ajayan, O. Stephan, C. Colliex, and D. Trauth, Science 265, 1212 (1994).

6. R.S. Ruoff and D.C. Lorents, Carbon 33, 925 (1995).

7. P. Kim, L. Shi, A. Majumdar, and P.L. McEUEN, Phys. Rev. Lett. 87, 215502 (2001). 7. A.C. Dillon, Nature 386, 377(1997).

8. G.E. Gadd, Science 277, 933 (1997).

9. P.J. Briffo, K.S.M. Santhanam, and P.M. Ajayan, Nature 406, 586 (2000).

10. S. Frank, P. Poncharal, Z.I. Wang, and W.A. de Heer, Science 280, 1744 (1998).

11. P.G. Collins, A. Zettl, H.Bando, A. Thess, and R.E. Smalley, Science 278, 100(1997).

12 W.A. de Heer, A. Chetalain, and D. Ugarte, Science 270, 1179 (1996).

13. S uman, Swapnil, et al. "Experimental investigation on influence of functionalized multi-walled carbon nanotubes on surface roughness in drilling of cfrp composites." International Journal of Mechanical and P roduction Engineering Research and Development (IJMPERD 8.3 (2018): 11331146.

14. H.J. Dai, J.H. Halfner, A.G. Rinzler, D.T. Colbert, and R.E. Smalley, Nature 384, 147 (1996).

15. S.Ghosh, A.K. Sood, and N.Kumar, Science 299, 1042 (2003).

16. H.D. Wagner, O,Lourie,Y.Feldman, and R. Tenne, Appl. Phys. Lett 72, 188 (1998).

17. P.M. Ajayan, J.M. Tour, Materials science: nanotube composites, Nature 447 1066-1068(2007).

18 A grawal, Prateek, S. R. P. Sinha, and S. U. B. O. D. H. Wairya. "Quantum dot cellular automata based p arity generator and detector: A review." International Journal of Electronics and Communication Engineering 5 (2016): 3.

19. B. Wetzel, F. Haupert, M.Q. Zhang, Epoxy nanocomposites with high mechanical and tribological performance, Compos. Sci. 
Technol. 63, 2055-2067(2003).

20. V. Mittal, Optimization of Polymer Nanocomposite Properties, Wiley-VchVerlag GmbH \&Co. KGaA, Weinheim, 2010.

21. I smail, Mahmud Rasheed, Muhannad Al-Waily, and Ameer A. Kadhim. "Biomechanical Analysis and Gait Assessment for Normal and Braced Legs." International Journal of Mechanical \& Mechatronics Engineering IJMME-IJENS 18.03 (2018).

22 J.P. Pascault, H. Sautereau, J. Verdu, R.J.J. Williams, Thermosetting Polymers, Marcel Dekker Inc., 2002.

23. E.M. Petrie, Epoxy Adhesive Formulations, McGraw-Hill Publishing, 2006.

24. D. Ratna, Handbook of Thermoset Resins, Smithers Rapra, 2009.

25. Prime, R. B. In Thermal Characterization of Polymeric Materials; Turi, E. A., Ed.; Academic Press: New York, pp 1379-1376, 1997. 
